\title{
Room Temperature Synthesis of Zinc Zno and Azo Thin Films by Successive Ionic Layer Adsorption and Reaction Method and Its Structural and Optical Characterization
}

\author{
${ }^{1}$ Ayodeji Oladiran Awodugba, ${ }^{2}$ Ayooye Abigael Olawoyin \\ ${ }^{1,2,}$ Department of Pure and Applied Physics, Ladoke Akintola University of Technology, P.M.B. 4000,
} Ogbomoso, Nigeria

\begin{abstract}
ZnO}$ and Al-doped $\mathrm{ZnO}$ (AZO) thin films were grown by Successive Ionic Layer Adsorption and Reaction (SILAR) method on a glass substrate from sodium zincate solution. Doping was achieved with controlled introduction of aluminum chloride. The technique involved multiple dipping of the substrate in an aqueous solution of sodium zincate kept at room temperature and a hot water bath kept at $95^{\circ} \mathrm{C}$ in which $\mathrm{ZnO}$ and $\mathrm{AZO}$ thin films were synthesized at $0.125 \mathrm{M}$ and $0.25 \mathrm{M}$ of sodium zincate $\left(\mathrm{Na}_{2} \mathrm{ZnO} \mathrm{O}_{2}\right)$ where 100 and 200 dippings were performed for each. The thickness of the layers were determined using Metler PB303 digital balance and a Radicon 10 mini- diffractometer (XRD) for the structural characterization while optical characterization was achieved with the use of a Jenway 6405 UV-Vis Spectrophotometer. The results revealed (002) peaks for $\mathrm{ZnO}$ thin films and (112) peaks for AZO thin films. Also the transmittances of the ZnO films were higher than those of $A Z O$ while AZO films have higher absorbance than those of $\mathrm{ZnO}$ films. The energy band gap of both $\mathrm{ZnO}$ and $\mathrm{AZO}$ were both found to be between $3.71 \mathrm{eV}$ and $3.80 \mathrm{eV}$, the values which are slightly higher than most reported values in literature.
\end{abstract}

Keywords - Absorbance, AZO, Energy bandgap, SILAR, Thin Films, XRD, ZnO

\section{Introduction}

$\mathrm{ZnO}$ is a wide band gap $(\sim 3.3 \mathrm{eV})$ group II-VI thin film semiconductor with a large exciton binding energy $(60 \mathrm{meV})$ which exhibits good piezoelectric, photo electric and optical properties and various usages such as anti-reflective coatings, gas sensors, transparent electrodes in solar cells [1] and whose study goes far back many decades and has enjoyed substantial interest in the research community partly because of its large exciton binding energy which could lead to lasing action based on exciton recombination even above room temperature. Researchers renewed interest is fueled by availability of high quality substrates and reports of p-type conduction and ferromagnetic behavior when doped with transition metals [2] .However, pure $\mathrm{ZnO}$ thin films lack stability in terms of thermal edging in air or corrosive environments [3]. Doping with III (p-type) ions such as Aluminum (Al), Gallium (Ga), Boron (B), etc is used to enhance their structural, optical and electrical properties. Doping is particularly done to get high transparency, stability and high conductivity. P-type doping using Aluminum was particularly suitable for this purpose.

The field is also fueled by theoretical predictions and perhaps experimental confirmation of ferromagnetism at room temperature for potential spintronics applications. [2] (Ozgur et al 2005). ZnO as group II-VI thin films has a tendency to grow with strong preferential orientation of various kinds of substrates including glass [4], sapphire [5] and diamond [6]. In order to reduce the strains and dislocation density in epitaxial $\mathrm{ZnO}$ and related films, closely lattice-matched substrates are favoured for growth. Sapphire substrates are commonly used for $\mathrm{ZnO}$ heteroepitaxial growth. Single crystal $\mathrm{ZnO}$ films have been grown on sapphire with a high degree of surface flatness which is essential for device fabrication. Glass was used as a preferred substrate in this research because of its high availability and low costs.

Researchers have used different physical and chemical techniques to grow both $\mathrm{ZnO}$ and in AZO. Amongst them are sputtering (dc sputtering, $\mathrm{rf}$ magnetron sputtering and reactive sputtering which is one of the most popular growth techniques for early $\mathrm{ZnO}$ investigations as compared to sol-gel [7] and chemical vapour deposition [8]. However, the conventional physical techniques generally produce good quality transparent films but are very expensive and are difficult to carry out in the industrial level. Chemical deposition techniques on the other hand, are relatively low cost processes and can be easily scaled up for industrial applications [9].

Among the chemical techniques, chemical bath deposition (CBD) is one of the simplest methods of depositing semiconductors and ceramic films [10]. It occurs due to substrate maintained in contact with dilute chemical bath by which film formation of substrate takes place when ionic product (IP) exceeds solubility product (SP) seems more appropriate than others such as spray pryolysis which is a high temperature process and also with a disadvantage with inconveniency in availability of choice of suitable precursor solution and its high temperature 
requirement. CBD often suffers from reproductibility, perhaps more than most chemical processes, a for $\mathrm{ZnO}$ films grown from alkaline solution onto glass. It requires a pre-deposition of $\mathrm{ZnO}$ on the substrate from other techniques known as seed layer [11] which brought about its modification known as Successive Ionic Layer Adsorption and Reaction method "SILAR" by [12]

The advantages of this method are its simplicity of working principal and low cost of apparatus. It is this renewed interest in $\mathrm{ZnO}$ which forms the basis of this research.

\section{Materials And Method}

Deposition of $\mathrm{ZnO}$ and $\mathrm{AZO}$ thin films was carried out from $0.125 \mathrm{M}$ and $0.25 \mathrm{M}$ sodium zincate $\left(\mathrm{Na}_{2} \mathrm{ZnO}_{2}\right)$ solution and hot water bath. The sodium zincate bath was prepared by adding sodium hydroxide $(\mathrm{NaOH})$ in zinc sulphate solution $\left(\mathrm{ZnSO}_{4} \cdot 7 \mathrm{H}_{2} \mathrm{O}\right)$. Aluminum doping of the sodium zincate was carried out by adding anhydrous aluminum chloride $\left(\mathrm{AlCl}_{3}\right)$ at 7 at \% doping concentration.

A pre-cleaned microscopic glass slide substrate which was first washed with detergent and rinsed in clean water severally and subsequently rinsed again in distilled water and kept in neat petri-dishes to avoid further contamination was used. Film deposition was carried out by alternatively dipping the pre-cleaned microscopic glass substrate in sodium zincate bath which is kept near room temperature for two seconds and in hot water bath maintained at $95^{\circ} \mathrm{C}$ for another two seconds. 100 and 200 dippings were performed each for the experiment.

The measurement of film thickness was carried out using gravimetry technique. The method involves measuring the weight change of the doped $\mathrm{ZnO}$ film formed on the substrate due to film deposition (M) together with the theoretical density of $\mathrm{ZnO}$.

Structural characterization and phase identification was carried out using X-Ray diffractometer with $\mathrm{CuK} \alpha$ radiation in a Radicon MD-10 mini diffractometer while the optical characterization was done using a Metler PB 303 UV-VIS spectrophotometer.

(a)

\section{Film thickness}

\section{Result And Discussions}

Table 1. Mass of $\mathrm{ZnO}$ and AZO deposited on substrate.

\begin{tabular}{|l|l|l|l|}
\hline Concentration & No of dippings & Mass of ZnO $(\mathrm{g})$ & Mass of AZO $(\mathrm{g})$ \\
\hline $0.125 \mathrm{M}$ & 100 & 0.113 & 0.116 \\
& 200 & 0.114 & 0.117 \\
\hline $0.25 \mathrm{M}$ & 100 & 0.114 & 0.117 \\
& 200 & 0.115 & 0.118 \\
\hline
\end{tabular}

From Table 1 and for both $0.125 \mathrm{M}$ and $0.25 \mathrm{M}$ baths, film thicknesses were found to depend in this case on the number of dippings, thus the film thickness can be controlled.

\section{Structural Characterization}

Figs. 1and 2 shows the X-ray diffraction (XRD) pattern of $\mathrm{ZnO}$ and $\mathrm{AZO}$ thin films of $0.125 \mathrm{M}, 100$ dippings deposited from sodium zincate bath. XRD spectra for other configurations are not shown. The material was scanned in the range $20^{\circ}-70^{\circ}$. The figures show the plot of pulses against $2 \theta$, where $\theta$ is the angle of incidence of X-ray beam. The $\mathrm{ZnO}$ films crystallize in the orthorombic phase with the prominent orientation along (002) plane at $29.34^{\circ}$ parallel with the substrate while the predominant orientation for AZO is along (102) plane at $19.27^{\circ}$.

The grain size, D, was estimated using the Scherrer's formula:

$$
\mathrm{D}=\frac{\mathrm{k} \lambda}{\beta \cos \theta}
$$

Where $\mathrm{k}$ is the shape factor with value in the neighborhood of 0.94 and $\beta$ is the full-width at halfmaximum (FWHM).

The dislocation density $\delta$ which represents the amount of defects in the film was determined from the $\delta=\frac{1}{\mathrm{D}^{2}}[14]$. 


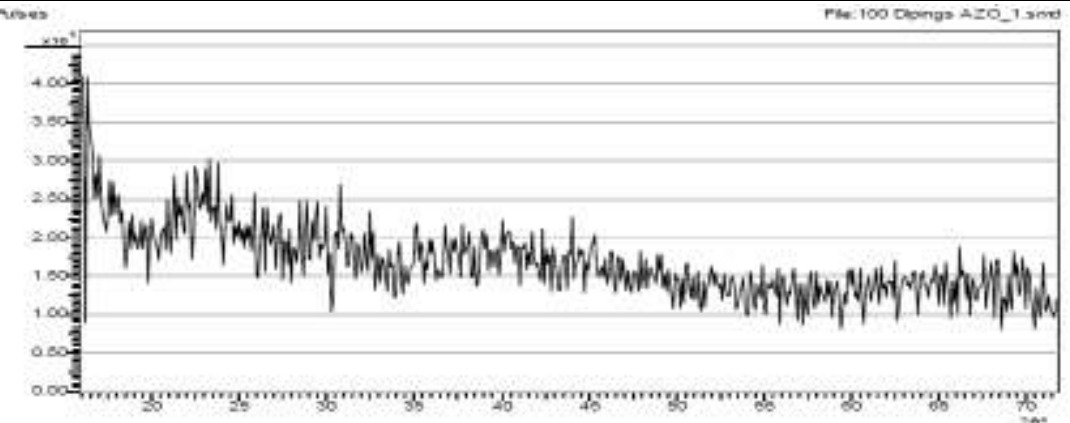

Figure 1: XRD pattern of undoped $\mathrm{ZnO}$ film at $0.125 \mathrm{M}, 100$ dippings

Also, the lattice parameters ' $a$ ' and ' $c$ ' were calculated by using the well-known analytical method [13], the $\mathrm{Zn}-\mathrm{O}$ bond length $\mathrm{L}$ [14] for $\mathrm{ZnO}$ was calculated using:

$$
L=\sqrt{\left(\frac{a^{2}}{3}+\left(\frac{1}{2}-u\right)^{2} c^{2}\right)}
$$

(2)

Where $\mathrm{u}$ the parameter in the wurtzite structure is given by:

$$
u=\frac{a^{2}}{3 c^{2}}+0.25
$$

and related to a/c ratio.

The parameters a, c, a/c and $\mathrm{L}$ are listed in Table 2

Table 2. The structural parameters of $\mathrm{ZnO}$ thin films for $\mathrm{ZnO}$ and $\mathrm{AZO}$

\begin{tabular}{|l|l|l|l|l|l|l|}
\hline & $\mathrm{a}(\AA)$ & $\mathrm{c}(\AA)$ & $\mathrm{a} / \mathrm{c}$ & $\mathrm{L}(\AA)$ & $\mathrm{D}(\mathrm{nm})$ & $\delta \times 10^{-4}(\mathrm{~nm})^{-2}$ \\
\hline $\mathrm{ZnO}$ & 5.884 & 9.886 & 0.595 & 3.623 & 31.0 & 10.41 \\
\hline $\mathrm{AZO}$ & 4.308 & 7.289 & 0.591 & 3.433 & 28.0 & 12.78 \\
\hline Ref.[14] & - & - & - & - & 31.9 & 9.80 \\
\hline
\end{tabular}

The large values of $\mathrm{D}$, the grain size is an indication of better crystallization of the films or both $\mathrm{ZnO}$ and $\mathrm{AZO}$ comparable to the best value of 31.9 reported by [14].

(c) Optical Characterization

(c)(i) Transmittance

The graphs above have been arranged in order of their decreasing transmittance, with $0.25 \mathrm{M}$ bath of 100 dippings of AZO having the highest transmittance, ranging from 0.6126-0.8922 at wavelengths between $338-1100 \mathrm{~nm}, 0.25 \mathrm{M}$ bath with 200 dippings of AZO having a transmittance values between 0.6001- 0.8257 at wavelengths between $471-1100 \mathrm{~nm}$. The bath containing $0.125 \mathrm{M}$ with 100 dippings of AZO has transmittance values between $0.5748-0.7555$ at wavelengths between $359-1100 \mathrm{~nm}$ while the bath with $0.25 \mathrm{M}$ and 100 dippings of $\mathrm{ZnO}$ has transmittance values between $0.7416-0.9128$ at wavelength of $419-1100 \mathrm{~nm} .0 .25 \mathrm{M}$ bath with 200 dippings of $\mathrm{ZnO}$ had a higher transmittance than $\mathrm{ZnO}$ of the same molarities and equal number of dippings with $\mathrm{ZnO}$ transmittance between $0.7012-0.8878$ at wavelengths of $357-1100 \mathrm{~nm}$ and $\mathrm{ZnO}$ transmittance values between $0.7031-0.8796$ at a wavelength between $391-1100 \mathrm{~nm}$.

It can be further deduced from the results gotten that the incorporation of $\mathrm{Al}$ in the $\mathrm{ZnO}$ has increased the transmittance but it should likewise be noted that $\mathrm{ZnO}$ has a lower transmittance wavelength than $\mathrm{AZO}$. 


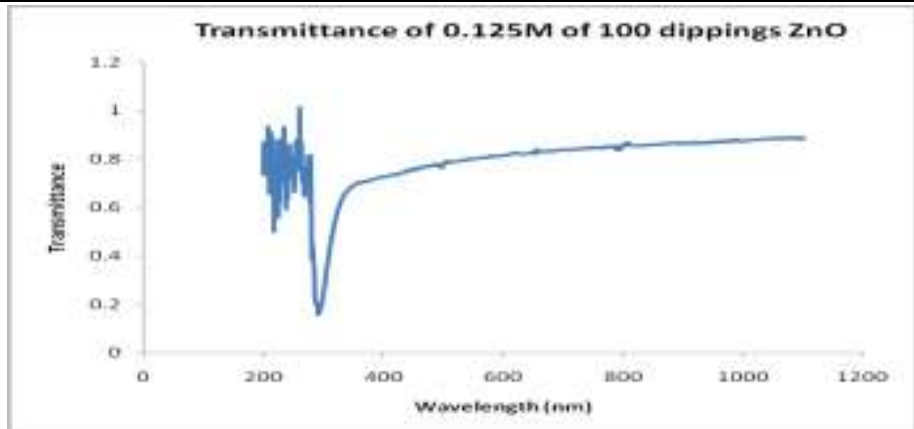

Figure 2: Transmittance of $\mathbf{0 . 1 2 5 M} 100$ dippings $\mathrm{ZnO}$

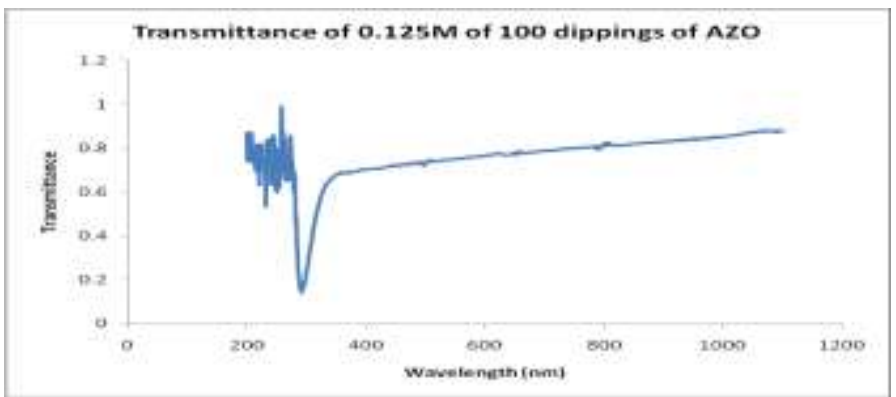

Figure 3: Transmittance of $0.125 \mathrm{M} 100$ dippings AZO

(c)(ii) Absorbance

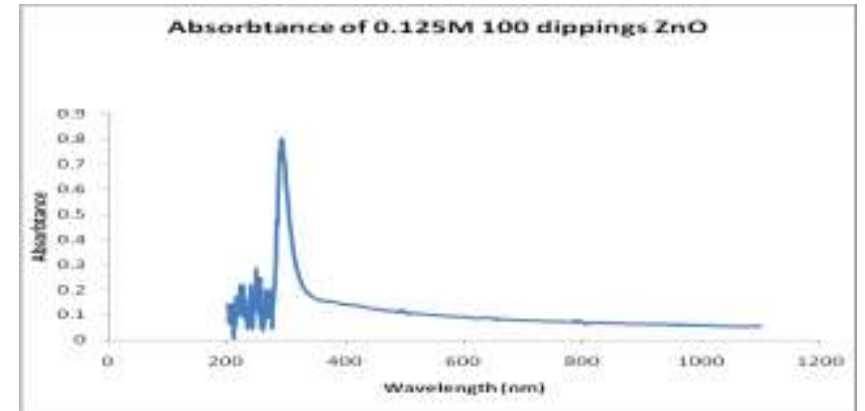

Figure 4: Absorbance for $\mathbf{0 . 1 2 5 M}, 100$ dipping of $\mathrm{ZnO}$

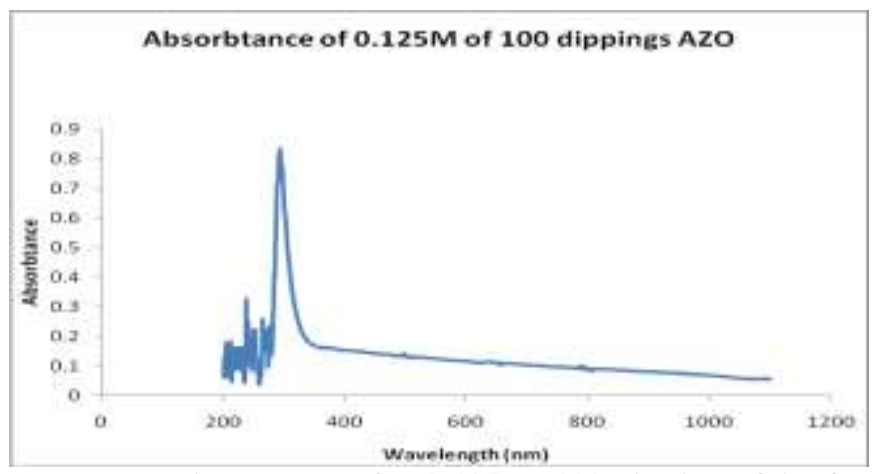

Figure 5: Absorbance for 0.125M, 100 dipping of AZO

The graphs above were arranged in order of decreasing absorbance. The absorbance values were calculated with wavelengths in the range of $287-1100 \mathrm{~nm}$. The results show that zinc oxide of $0.25 \mathrm{M}$ with 200 dippings has the highest absorbance between $0.863-0.114$, followed by zinc oxide of $0.25 \mathrm{M}$ with 100 dippings having values between $0.706-0.038$. Zinc oxide with $0.125 \mathrm{M}$ at 100 dippings has absorbance values between $0.734-0.050$, followed by Aluminum-doped zinc oxide with $0.125 \mathrm{M}$ of 100 dippings having values between 0.724 - 0.081 . For the $0.25 \mathrm{M}$ bath with 200 dippings, aluminum doped zinc oxide have values between 0.657 - 
0.054 , and aluminum doped zinc oxide in bath of $0.25 \mathrm{M}$ and 100 dippings have absorbance values between $0.642-0.054$.

\section{(c)(iii) Energy Band Gap}

The energy band gap of the films were determined from the plot of the square of the product of coefficient absorbance and energy of photon $\mathrm{E}(\mathrm{h} \square)$ against energy of photon $\mathrm{E}(\mathrm{h} \square)$ given rise to Figs. 13 - 18 .

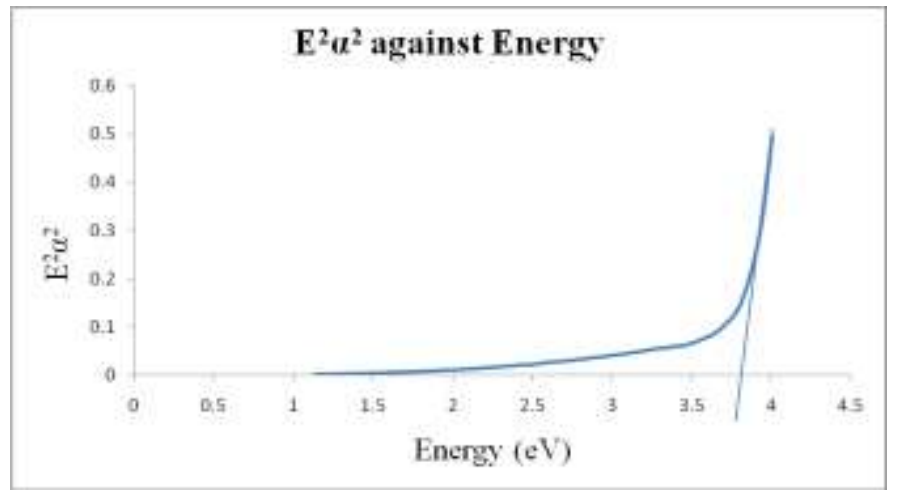

Figure 6: Energy bandgap of $0.125 \mathrm{M}, 100$ dippings $\mathrm{ZnO}$ thin film.

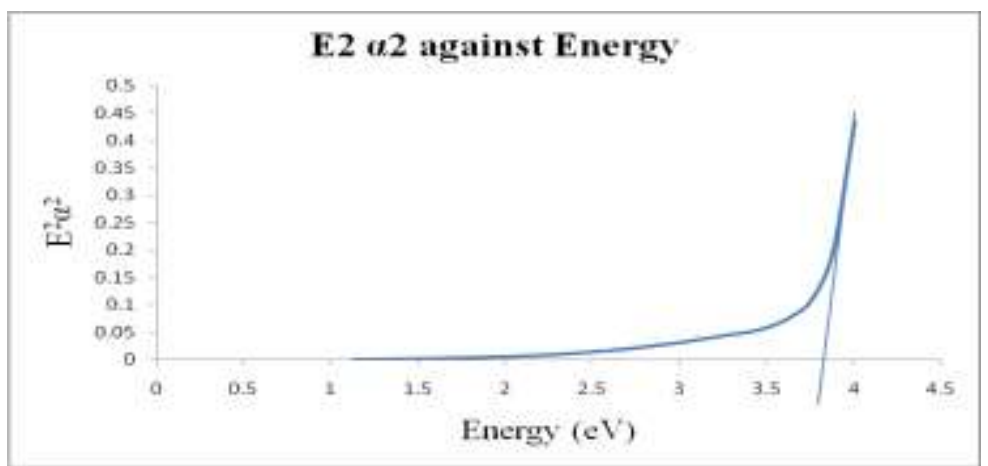

Figure 7: Energy band gap of 0.125M, 100 dippings AZO thin film.

The energy band gap for both Zinc oxide $\mathrm{ZnO}$ and Aluminum doped Zinc oxide AZO were found to be in the range between $3.75-3.80 \mathrm{eV}$.

\section{Conclusions}

Aluminum was successfully incorporated into $\mathrm{ZnO}$ thin films via SILAR method at $7 \mathrm{~atm} \%$ and the effect was observed from the increase in transmittance of doped $\mathrm{ZnO}$ to undoped $\mathrm{ZnO}$ thin films. Obviously from Table 1, increase in molarity can lead to increase in thickness of deposited film on the substrate. Also, the band gap gotten slightly differs from the ones reported in literatures. This slight deviation may be due partly to the method and substrate used and the temperature of deposition, the ambient room temperature in this work. Work is on-going to study the effects of these three factors on the optical and electrical characteristics of $\mathrm{ZnO}$ thin films, both doped and undoped. Also, the effect of annealing on the structural and optical characteristics is being investigated.

\section{Acknowledgement}

The authors would like to sincerely appreciate Mr Ayoola C.T of Science Laboratory technology department of Ladoke Akintola University of Technology, Ogbomoso and also Dr Pascal T.O. of Center for Energy Research \& Development (CERD) Obafemi Awolowo University, Ile-Ife for their immense contributions and valuable suggestions throughout the work and Engineering Materials Development Institute (EMDI) Akure for the provision of some of the research facilities. 


\section{References}

[1]. Studenikin SA, Golego N and Cocivera M, Fabrication of green and orange photoluminescence, undoped ZnO films using Spray pyrolysis.

[2]. J.Appl. Phys. 84(4) 1998 2287-2294

[3]. Ozgur, U., Ya. I., Alivov, C., Liu, A., Teke, M.A., Reshchikov, S., Dogan, Avrutin, V. Cho. S.J. and Morkoc, H. A comprehensive review of $\mathrm{ZnO}$ materials and devices, Journal of applied Physics 98, 2005, 041301.

[4]. Jimenez-Gonzalez, A. E. Modification of ZnO Thin Films by Ni, Cu, and Cd doping, Journal of Solid-State Chemistry 28 (1997), $176-180$.

[5]. T.Yamamoto, T.Shiosaki, and A.Kawabata, Characterization of $\mathrm{ZnO}$ piezoelectric films prepared by rf planar-magnetron sputtering, J.Appl. Phys.51, 3113 (1980).

[6]. T.Mitsuyu, S.Ono, and K.Wasa, Structures and SAW properties of rf-sputtered single-crystal films of ZnO on sapphire, J.Appl. Phys. 51,2464 (1980)

[7]. A.Hachigo, H.Nakahata, K.Higaki, S.Fujii, and S.Shikata, Heteroepitaxial growth of ZnO films on diamond (111) plane by magnetron sputtering, Appl. Phys. Lett.65, 2556 (1994).

[8]. Harish Bahadur, Ram Kishore, K.N. Sood, Rashmi. D.K Suri, M. Kar, A. Basu, R.K Sharma, and Sudhir Chandra, Preparation and Characterization of ZnO Thin films of silicon substrate using Sol-gel process, Physics of Semiconductor Devices (IWPSD-2003), Mondal, X., Kanta, K.P and Mitra, P. Preparation of Al-doped ZnO (AZO) Thin Film by SILAR, Jounal of Physical Sciences, Vol.12, 2008, 221-229.

[9]. Tiku S.K, C.K Lan and K.M Lakin , Chemical vapour deposition of ZnO epitaxial films on sapphire, Applied physics letter 36, 1980, 318-320.

[10]. Michael Kokotov, Ariel Biller, and Gary Hodes, Reproducible Chemical Bath Deposition of ZnO by a One-Step Method: The Importance of "Contaminants" in Nucleation.

[11]. J. Chem. Mater.2008, 20 4542-4544.

[12]. Hodes, G., Chemical Solution Deposition of Semiconductor Films (Marcel Dekker; New York 2003).

[13]. Nicolau, Y. F. and Menard, J.C. , Growth of ZnS, CdS and ZnO Thin films by SILAR

[14]. J. Cryst. Growth, 92 (1988) 128-132.

[15]. G.B. Williamson, R.C. Smallman, Philos. Mag. (1956) 1, 34 S. Ilican, Y. Caglar, and M. Caglar Preparation and Characterization of $\mathrm{ZnO}$ thin films deposited by sol-gel spin coating coating method.

[16]. Journal of Optoelectronics and Advanced Materials Vol. 10, No 10 (2008) 2578-2583 